\title{
Effect of N-Acetyl Cysteine on acute kidney injury in patients with colistin used in intensive care; retrospective study
}

\section{Yoğun bakımda kolistin kullanılmış hastalarda mukolitik doz N-Asetil Sisteinin akut böbrek hasarına etkisi; retrospektif inceleme}

\author{
Arif Timuroğlu, Selda Muslu, Saadet Menteş, Süheyla Ünver \\ Doktor Abdurrahman Yurtaslan Ankara Onkoloji Eğitim Ve Araştırma Hastanesi, Ankara, Türkiye
}

\begin{abstract}
ÖZET
GİRIŞ ve AMAÇ: Akut böbrek hasarı $(A B H)$ intravenöz kolistin kullanan kritik hastalarda sıklıkla görülebilen bir durumdur. Oluşan nefrotoksisite doz bağımlıdır ve genellikle geri dönüşümlüdür, kalıcı böbrek hasarı nadiren görülür. N-Asetil Sistein (NAC) kullanımının böbrek hasarından koruyucu etkisi uzun yıllardır araştırılan bir konu olmuştur. Biz bu çalışmada yoğun bakım ünitemizde intravenöz kolistin kullanmış olan hastalarımızda beraberinde mukolitik amaçlı NAC kullananlarda akut böbrek hasarını incelemeyi amaçladık. YÖNTEM ve GEREÇLER: Ankara Onkoloji Hastanesi Anestezi Yoğun Bakım Ünitesi'nde Haziran-Aralık 2017 tarihleri arasında antimikrobiyal tedavi olarak intravenöz yoldan beş gün ve üzeri kolistin kullanan 18 yaş üzeri otuz beş hasta çalışmaya alındı. Hastalar mukolitik dozda NAC kullanıp kullanmamalarına göre retrospektif olarak incelendi ve iki gruba ayrıldı. NAC kullanan yirmi üç hasta kullanmayan on iki hasta tespit edildi. Mukolitik dozda kullanılan NAC'ın akut böbrek hasarı ile ilişkisi incelendi. Elde edilen veriler SPSS 24.0 programında frekans, çapraz tablolar ve Mann Whitney-U analizleri ile değerlendirildi. BULGULAR: Kolistin kullanan hastaların yirmi altısında KDIGO kriterlerine göre ABH gelişti (\%74,3). NAC kullanan ve kullanmayan grup arasında ABH oluşma oranı, mortalite oranı, mekanik ventilatör gün sayısı, yoğun bakım yatış süresi arasında fark bulunamadı. Yatış sırasındaki eGFR düzeyi ile kolistin kullanımı sonrası ABH gelişimi arasında ilişki bulunamadı.

TARTIŞMA ve SONUÇ: Bu retrospektif çalışmada mukolitik amaçlı NAC kullanımının kolistin nefropatisini engellemede başarısız olduğu bulundu. Hayvan çalışmalarında ve in vitro çalışmalarda yüksek doz NAC'ın kolistinin böbrek hasarı etkisinden koruyuculuğu gösterilmiş olmasına rağmen, yoğun bakımda yatmakta olan hastalarda mukolitik dozda kullanılan NAC'ın kolistine bağlı oluşan ABH'dan koruyucu etkisi görülmedi.
\end{abstract}

Anahtar Kelimeler: kolistin, akut böbrek hasarı, N-Asetilsiste

\footnotetext{
ABSTRACT

INTRODUCTION: Acute kidney injury (AKI) is a common condition in critically ill patients using intravenous colistin. Nephrotoxicity is dose-dependent and usually reversible. The protective effect of the use of N-Acetyl Cysteine (NAC) on kidney injury has been the subject of research for many years. In this study, we aimed to investigate the AKI in our patients who have used intravenous colistin in our intensive care unit with N-Acetyl Cysteine for mucolytic use.

METHODS: In the Intensive Care Unit of Ankara Oncology Hospital between June-December 2017, thirty-five patients over 18 years of age who were using colistin via intravenous route for five days and above as antimicrobial therapy were included in the study. Patients were retrospectively examined and divided into two groups according to whether they were using NAC in the mucolytic dose. Twelve patients who did not use NAC and twenty-three patients who used NAC were detected. The relationship of NAC with AKI was investigated. The data were analysed by frequency, cross-tables and Mann Whitney-U analysis in SPSS 24.0 program. RESULTS: In twenty-six of the patients who were using colistin, AKI developed according to the criteria of KDIGO (74.3\%). There was no significant difference between AKI rate, mortality rate, number of days of mechanical ventilation and ICU length of stay among the NAC group and non-NAC group. There was no relationship between eGFR level during hospitalization and development of AKI after use of colistin. Adress for correspondence: Arif Timuroğlu, Dr.Abdurrahman Yurtaslan Ankara Onkoloji Eğit. Ve Araş. Hastanesi Mehmet Akif Ersoy Mahallesi 13. Cadde No: 56 Yenimahalle 06200 Ankara, Türkiye 
DISCUSSION and CONCLUSION: It was found that mucolytic use of NAC was unsuccessful in inhibiting the nephropathy of the colistin. Although high doses of NAC have been shown to be protective against kidney damage in animal studies and in vitro studies, no protective effect of NAC due to colistin was observed in patients who were in intensive care.

Keywords: colistin, acute Kidney Injury, N-Acetylcysteine

\section{GİRIŞ}

Akut böbrek hasarı intravenöz kolistin kullanan kritik hastalarda sıklıkla görülebilen bir durumdur. Oluşan nefrotoksisite doz bağımlıdır ve genellikle geri dönüşümlüdür, kalıcı böbrek hasarı nadiren görülür (1). Klinik görünümde kreatinin klerensinde azalma, proteinüri, silindirüri veya oligüri oluşabilir (2). NAsetil Sistein (NAC) kullanımının böbrek hasarından koruyucu etkisi uzun yıllardır araştırılan bir konu olmuştur. Özellikle radyo kontrast nefropatisinden korunmak amaçlı kullanımı son yıllara kadar süregelmiştir (3). Yüksek doz NAC'ın kolistin nefropatisinde böbrek koruyucu etkisi hayvan çalışmasında denenmiş ve olumlu sonuç elde edilmiştir (4). Kolistin nefrotoksisitesinde NAC kullanımı ile ilgili insanlar üzerinde yapılmış bir çalışma literatürde bulunamadı.

$\mathrm{Bu}$ çalışmada yoğun bakım ünitemizde intravenöz kolistin tedavisi uygulanmış olan hastalarda mukolitik amaçlı NAC kullanımının akut böbrek hasarına etkilerini incelemeyi amaçladık.

\section{YÖNTEM ve GEREÇ}

\section{Ankara Onkoloji Hastanesi Anestezi} Yoğun Bakım Ünitesinde Haziran-Aralık 2017 tarihleri arasında antimikrobiyal tedavi olarak intravenöz olarak beş gün ve üzeri kolistin kullanan 18 yaş üzeri otuz beş hasta çalışmaya alındı, verileri retrospektif olarak incelendi. 18 yaş altı olan hastalar, radyolojik görüntüleme amaçlı kontrast madde uygulanan hastalar, beş günden daha az kolistin kullanan hastalar çalışma dışı bırakıldı. Mukolitik NAC dozu (400-1200 mg), Seetal D ve ark.'larının (5) yaptığı çalışmaya göre tanımlandı ve hastalar mukolitik dozda NAC kullanıp kullanmamalarına göre iki gruba ayrildı.

NAC kullanan yirmi üç hasta kullanmayan on iki hasta tespit edildi. Hastaların yaş, cinsiyet, beden kitle indeksi, primer hastalıkları, kemoterapiradyoterapi uygulanması, APACHE-II (akut fizyoloji ve kronik sağlık değerlendirmesi-acute physiology and chronic health evaluation), SOFA (ardiş1k organ yetmezliği değerlendirmesisequential organ failure assessment) skoru, albümin-total bilirubin düzeyleri hastane elektronik kayit sisteminden ve hasta dosyalarından incelendi. Mukolitik dozda kullanılan NAC'ın ABH (akut böbrek hasarı) ile ilişkisi incelendi. Hastaların yoğun bakıma kabul edildiği zaman ve kolistin kullanırken eGFR (tahmini glomerüler filtrasyon hiz1-estimated glomerular filtration rate) değerleri hesapland1. eGFR hesaplanması için CKDEPI (kronik böbrek hastalığ epidemiyoloji iş birliği-chronic kidney disease epidemiology collaboration) formülü kullanıldı (6). ABH tanısı için günümüzde kullanılan KDIGO (böbrek hastalığ1; küresel sonuçların iyileştirilmesi-kidney disease: improving global outcomes) tan1 kriterleri kullanıldı (7). Çalışma verileri işlendikten sonra KDIGO kriterleri kullanılarak elde edilen sonuçlar incelendi. 
Çalışmamızdaki ABH oranlarının literatür verilerine göre daha yüksek çıkması üzerine literatürdeki verilerin $\mathrm{ABH}$ tanı kriterlerini nasıl kabul ettikleri araştırıldı. İncelenen çalışmalarda $\mathrm{ABH}$ tanısı için kabul edilmiş standart bir yöntem olmadığ1 görüldü ve KDIGO kriterlerinin kabulünden önce kullanılan RIFLE (risk, hasar, yetmezlik, böbrek fonksiyon kayb1 ve son dönem böbrek yetmezliği-risk, injury, failure, loss of kidney function, and end-stage kidney disease) kriterleri kullanılarak hasta verileri tekrar değerlendirildi (8). RIFLE ve KDIGO kriterleri tablo 1'de gösterilmiştir.

Elde edilen veriler SPSS 24.0 programında frekans, çapraz tablolar, Mann Whitney-U analizleri ile değerlendirildi. $\quad \mathrm{p}<0,05$ anlamlı olarak kabul edildi.

\section{BULGULAR}

Kolistin kullanan hastaların yirmi altısında KDIGO kriterlerine göre $\mathrm{ABH}$ gelişti (\%74,3). NAC kullanan ve kullanmayan grupların demografik verileri, APACHE II, SOFA skorları, serum albümin ve total bilirubin düzeyleri, 24 saatte kullanılan toplam furosemid dozu, 24 saatlik ortalama idrar miktarı ve sıvı dengesi arasında fark bulunamadı (Tablo 2). NAC kullanan ve kullanmayan gruplar arasında akut böbrek hasarı oluşma oranı, mortalite oranı, mekanik ventilatör gün sayısı, yoğun bakım yatış süresi arasında fark bulunamadı (Tablo 3). ABH tanısı için RIFLE kriterlerinin "failure" ve üzeri basamakları kullanıldığı zaman ABH oranı $\% 17,1$ olarak bulundu. RIFLE-F basamağına benzer olan KDIGO evre 3 $\mathrm{ABH}$ tanısı için kullanıldığında ise $\mathrm{ABH}$ oran1 \%22,9 olarak bulundu (Tablo 4). Yatış sırasındaki eGFR düzeyi ile kolistin kullanımı sonrası ABH gelişimi incelendi. Yoğun bakım yatışı sırasında, eGFR' si 50'nin altında olan on iki hastadan kolistin kullanımı sonrası yedisinde $\mathrm{ABH}$ gelişirken $(\% 58,3)$ yatış eGFR' si 50 ve üzerinde olan yirmi üç hastadan on dokuzunda ABH gelişti $(\% 82,6)$. Yoğun bakım yatışı sırasındaki eGFR düzeyi ile kolistin kullanımı sonrasında oluşan nefropati arasında ilişki bulunamadı $(p=0,22)$ (Şekil 1). ABH gelişen yirmi altı hastadan on sekizinde bir malignite varken sekizinde malignite saptanmad $(p=0,68)$.

\section{TARTIŞMA}

$\mathrm{Bu}$ retrospektif çalışmada, mukolitik amaçlı NAC kullanımının kolistin nefropatisinden koruyuculuğu incelendi ve NAC'1n kolistin nefropatisini engellemede başarısız olduğu bulundu.

Kolistin, çoklu ilaç direnci olan gram negatif bakterilere karşı kullanılan bir ilaçtır. Özellikle acinetobacter baumannii, pseudomonas aeroginosa ve klebsiella pneumoniae'ya karşı etkin bir şekilde kullanılmaktadır ve son y1llarda uygulama sıklığ giderek artmıştır $(9,10,11)$. Kolistin kullanımı ile ilgili endişe oluşturan durumlardan siklıkla görüleni nefrotoksisitedir. Kolistin ile oluşan akut böbrek hasarı sıklığı literatürde \%11 ile \%53,5 arasında değişmektedir (12). Literatürdeki nefrotoksisite oranları arasındaki farklılıklar ABH tanısının farklı yöntemler ile konulmasına bağlıdır. Bazı çalışmalar ABH tanısı için RIFLE kriterlerinin her aşamasını kullanırken, bazıları sadece "F-failure" ve daha ileri aşamaları kullanmışlardır. Serum kreatinin 
düzeyinin $2 \mathrm{mg} / \mathrm{dL}$ 'den yüksek olmasını böbrek hasarı için kriter olarak kabul eden yayınlar da mevcuttur (13). Çalışmamızda ABH tanısı için KDIGO kriterleri kullanıldı ve $\mathrm{ABH}$ oranı \%74,3 olarak bulundu. Çalışmamızdaki ABH oranının literatüre göre oldukça yüksek çıkmasının sebebinin ABH tanısı için KDIGO kriterlerini kullanmamız olduğunu düşünmekteyiz. Bunu desteklemek için çalışmamızdaki verileri tekrar değerlendirip RIFLE kriterlerinden " $F$ failure" ve daha sonraki basamaklardaki hasta sayısını hesapladık ve toplam 6 hastanın $(\% 17,1)$ bu gruba girdiğini bulduk. Yeniden hesaplanarak bulunan bu oran literatür ile benzerdir. RIFLE-F kriteri ile benzerlik gösteren KDIGO evre 3 hastaların sayısı ise $8 \quad(\% 22,9)$ olarak bulundu (Tablo 4). Ülger ve ark'larının yaptığı bir çalışmada, ABH tanısı sıklığının KDIGO kriteri kullanıldığında RIFLE kriterine göre daha yüksek olduğu gösterilmiştir (14). Tsai ve ark'larının 167 ECMO hastasını incelediği bir diğer çalışmada da KDIGO kriterleri ile 142 hastada $\mathrm{ABH}$ tanis1 varken RIFLE kriterleri ile bu sayı 126'ya inmektedir (15). $\mathrm{Bu}$ da bizim bulgularımızdaki KDIGO evre 3 ile RIFLE-F kriterleri kullanılarak ABH tanısı düşünülen hastaların sayısının farklı olması ile uyumludur.

$\mathrm{N}$-asetil sistein (NAC), 50 y1l önce mukolitik ajan olarak kullanıma girmiş ve asetaminofen toksisitesi, doksurobisinin indüklediği kardiyotoksisite ve radyokontast nefropatisi tedavisi için sıklıkla 600 mg/gün ile 150mg/kg/gün doz aralığında kullanılmıştır $(16,17,18,19)$. NAC, inflamatuar sitokinleri baskılar, glutatyon metabolizmasında rol alır, anti- inflamatuar ve antioksidan etki mekanizmasına sahiptir (15,20). Antioksidan özelliklerinin yanı sıra oksijenasyonu iyileştirir, serbest radikal hasarını azaltır, mikrodolaşımı olumlu etkileyerek organ perfüzyonunu artırır $(16,21)$. Yapılan hayvan çalışmalarında NAC kullanımının vankomisin, gentamisin, ifosfamid, lityum, sisplatin ve kontrast madde uygulanmasına bağlı nefrotoksisiteyi azalttığ 1 gösterilmiştir $(22,23,24,25,26,27)$. Kontrast madde nefropatisini önlemek amaçlı NAC kullanımı ile ilgili olumlu ve olumsuz sonuçlar içeren çeşitli yayınlar mevcuttur (3). Fakat son yıllarda yapılan çalışmalar neticesinde NAC'1n kontrast madde nefropatisinden koruyuculuğu artık tartışmalı hale gelmiştir (28).

Kolistin kullanan hastalarda NAC uygulanması ile nefrotoksisite arasındaki ilişki daha önce iki deneysel çalışmada incelenmiştir. Özyılmaz ve ark'ları yaptıkları bir hayvan çalışmasında 150 $\mathrm{mg} / \mathrm{kg}$ dozunda NAC kullanmış ve nefrotoksisite açısından olumlu sonuç elde etmişlerdir (4). Ceylan ve ark'larının yaptığı bir diğer hayvan çalışmasında ise $300 \mathrm{mg} / \mathrm{kg}$ dozunda NAC kullanılmış ve kolistin kullanımına bağlı böbrek hücresi apopitozunda azalma gösterilmiştir (29). Bizim çalışmamızda günlük ortalama uygulanan NAC dozu 816,3 mg olarak hesapland1. $\mathrm{Bu}$ da yaklaşı 10-12 $\mathrm{mg} / \mathrm{kg}^{\prime} l \mathrm{k}$ bir doza denk gelmektedir. Mukolitik amaçlı düşük dozda NAC kullanımı ile oluşan nefropati arasında NAC kullanılmayanlara göre bir fark bulamadık. Yapılan hayvan çalışmalarında çok daha yüksek dozlarda NAC kullanılmış ve nefrotoksisite koruyucu etki elde edilmiştir. Böbrek hasarı oluşturma 
ihtimali olan ilaç kullanımı öncesi profilaktik NAC kullanım süresi ile ilgili literatürde bir öneri bulunmamakla beraber yapılan çalışmalar incelendiğinde, NAC'in nefropatik ajan verilmeden hemen önce veya yaklaşık 6 saat önce uygulandığını gördük (30). Bizim çalışmamızda hastaların ne kadar süredir NAC kullandığg ile ilgili bir veriye ulaşılamadı.

Çalışmamızın bazı kısıtlamaları mevcuttur. Öncelikle, çalışmanın retrospektif, tek merkezli ve sadece yoğun bakımda yatan hastaları içermesi elde edilen verilerin genellemesini kısıtlamıştır. Hastaların verilerine ulaşmadaki kısıtlılıklar dolayısıyla vazopressör kullanımı, kan basıncındaki değişiklikler, santral venöz basınç gibi nefrotoksisiteyi etkileyecek durumlar değerlendirilmeye alınamamıştır.

\section{SONUÇ}

Sonuç olarak, hayvan çalışmalarında ve in vitro çalışmalarda yüksek doz N-Asetil Sisteinin kolistinin böbrek hasarı etkisinden koruyuculuğu gösterilmiş olmasına rağmen, yoğun bakımda yatmakta olan hastalarda mukolitik dozda kullanılan N-Asetil Sisteinin kolistine bağl1 oluşan akut böbrek hasarından koruyucu etkisi görülmedi. Daha farklı doz ve sürede NAC kullanımının etkisini araştıran çalışmalara gereksinim olduğu düşünüldü.

\section{Çıkar Çatışması: Yok}

Tablo 1. RIFLE ve KDIGO kriterleri

\begin{tabular}{|c|c|c|c|}
\hline & \multicolumn{2}{|c|}{ Serum kreatinin } & \multirow[t]{2}{*}{ İdrar çıkış1 } \\
\hline & RIFLE & KDIGO & \\
\hline Tanım & $\begin{array}{l}\mathrm{SCr} \text { artış1 } \geq \% 50, \\
7 \text { gün içerisinde }\end{array}$ & $\begin{array}{l}\mathrm{SCr} \text { artışı } \geq 0,3 \mathrm{mg} / \mathrm{dL}, 48 \\
\text { saat içerisinde } \\
\text { veya } \\
\geq \% 50,7 \text { gün içerisinde }\end{array}$ & $\begin{array}{l}<0,5 \mathrm{~mL} / \mathrm{kg} / \mathrm{sa}, 6 \text { saat } \\
\text { boyunca }\end{array}$ \\
\hline Evreleme & & & \\
\hline $\begin{array}{l}\text { RIFLE-Risk } \\
\text { KDIGO evre } 1\end{array}$ & $\begin{array}{l}\text { SCr artış1 } \geq \% 50 \text { veya } \\
\text { GFR'de } \% 25 \text { 'ten fazla } \\
\text { azalma }\end{array}$ & $\begin{array}{l}\mathrm{SCr} \text { artış } 1 \geq 0,3 \mathrm{mg} / \mathrm{dL}, 48 \\
\text { saat içerisinde } \\
\text { veya } \\
\geq \% 50,7 \text { gün içerisinde }\end{array}$ & $\begin{array}{l}<0,5 \mathrm{~mL} / \mathrm{kg} / \mathrm{sa}, \\
6 \text { saat boyunca }\end{array}$ \\
\hline $\begin{array}{l}\text { RIFLE-Injury } \\
\text { KDIGO evre } 2\end{array}$ & $\begin{array}{l}\text { SCr artışı } \geq \% 100 \text { veya } \\
\text { GFR'de } \% 50 \text { 'den fazla } \\
\text { azalma }\end{array}$ & $\mathrm{SCr}$ artışı $\geq \% 100$ & $\begin{array}{l}<0,5 \mathrm{~mL} / \mathrm{kg} / \mathrm{sa}, 12 \mathrm{saat} \\
\text { boyunca }\end{array}$ \\
\hline RIFLE-Failure & $\begin{array}{l}\text { SCr artışı } \geq \% 200 \text { veya } \\
\text { GFR'de } \% 75 \text { 'ten fazla }\end{array}$ & $\begin{array}{l}\mathrm{SCr} \text { artış } 1 \geq \% 200 \text { veya } \\
\mathrm{SCr} \geq 4 \mathrm{mg} / \mathrm{dL} \text { veya }\end{array}$ & $\begin{array}{l}<0,3 \mathrm{~mL} / \mathrm{kg} / \mathrm{sa}, 24 \text { saat } \\
\text { boyunca }\end{array}$ \\
\hline
\end{tabular}

Adress for correspondence: Arif Timuroğlu, Dr.Abdurrahman Yurtaslan Ankara Onkoloji Eğit. Ve Araş. Hastanesi Mehmet Akif Ersoy Mahallesi 13. Cadde No: 56 Yenimahalle 06200 Ankara, Türkiye

e-mail: ariftimuroglu@yahoo.com

Available at www.actaoncologicaturcica.com

Copyright $\odot$ Ankara Onkoloji Hastanesi 


\begin{tabular}{|l|l|l|l|}
\hline KDIGO evre 3 & azalma & RRT ihtiyacı & veya \\
& veya & & Anüri 12 saat boyunca \\
& $\mathrm{SCr} \geq 4 \mathrm{mg} / \mathrm{dL}$ (akut sürede \\
& & & \\
\hline RIFLE-Loss & $>4$ hafta RRT ihtiyacı & & \\
\hline RIFLE-End stage & $>3$ ay RRT ihtiyac1 & & \\
\hline
\end{tabular}

RIFLE: Risk, Injury, Failure, Loss of Kidney Function, and End-stage Kidney Disease, KDIGO: Kidney Disease Improving Global Outcome; SCr, serum kreatinin, GFR, glomerüler filtrasyon hızı; RRT: renal replasman tedavisi

Tablo 2. N-Asetil Sistein kullanan ve kullanmayan grupların karşılaştırılması (Ortalama \pm SD)

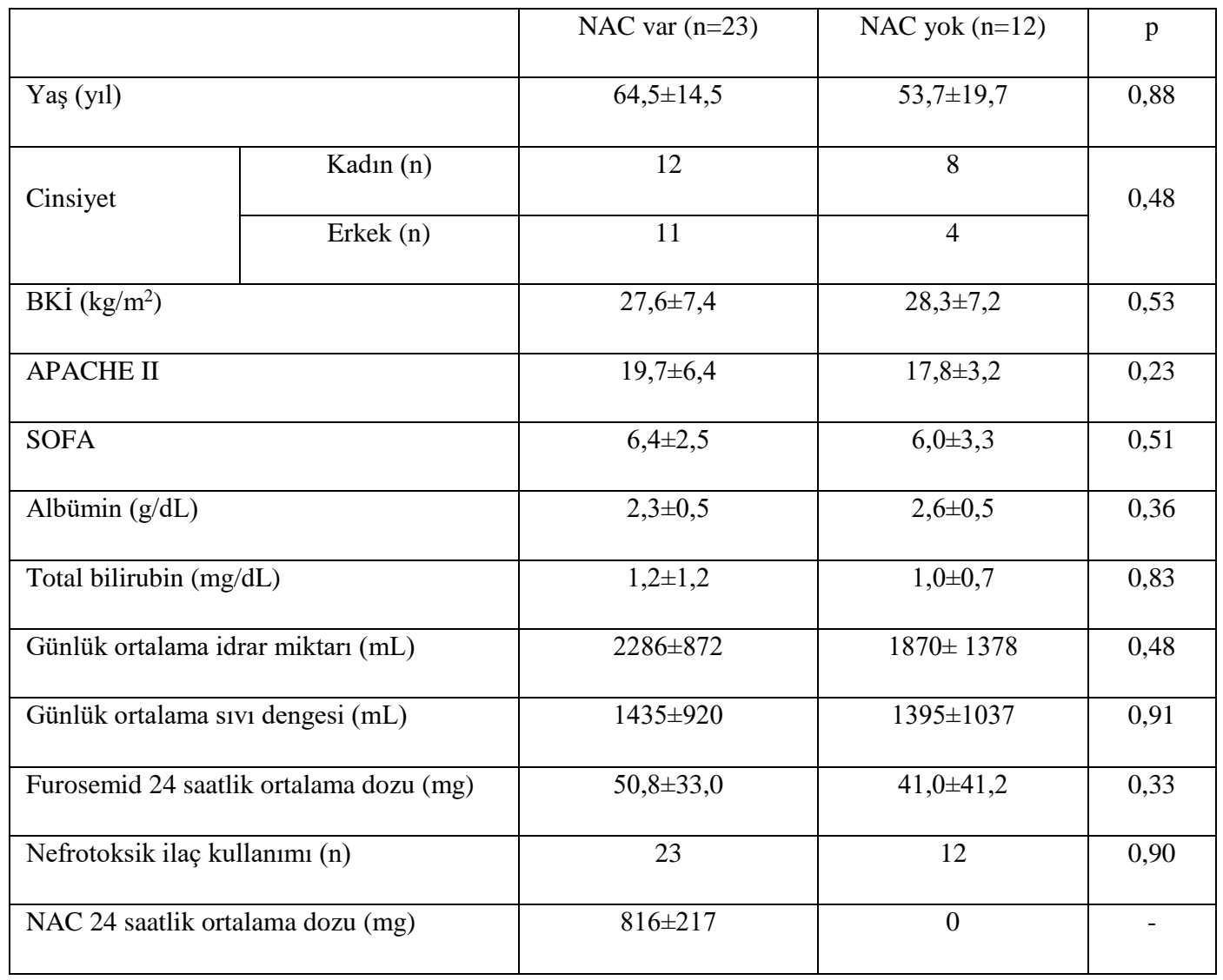

Veriler ortalama değerlerdir, \pm standart sapma değerleridir, $n$; hasta sayısı olarak verildi, $\mathrm{p}<0,05$ anlamlı kabul edildi. BKİ: beden kitle indeksi, APACHE: Acute Physiology and Chronic Health Evaluation, SOFA: Sequential Organ Failure Assessment, NAC: N-Asetil Sistein 
Tablo 3. N-asetil sistein kullanan ve kullanmayan grupların akut böbrek hasarı oluşma oran1, mortalite oran1, mekanik ventilatör gün sayıs1, yoğun bakım yatış süresi bakımından karşılaştırılması (Ortalama \pm SD)

\begin{tabular}{|l|c|c|c|c|}
\hline & NAC var (n=23) & NAC yok $(\mathrm{n}=12)$ & Toplam (n=35) & $\mathrm{p}$ \\
\hline $\mathrm{ABH}(\mathrm{n}, \%)$ & $19(82,6)$ & $7(82,6)$ & $26(74,3)$ & 0,22 \\
\hline Mortalite (n, \%) & $19(82,6)$ & $8(66,7)$ & $27(77,1)$ & 0,40 \\
\hline $\begin{array}{l}\text { Mekanik ventilatör } \\
\text { süresi (gün) }\end{array}$ & $19,7 \pm 14,1$ & $16,1 \pm 12,9$ & $18,5 \pm 13,7$ & 0,49 \\
\hline $\begin{array}{l}\text { Yoğun bakım yatı̧̧ } \\
\text { süresi (gün) }\end{array}$ & $23,8 \pm 12,4$ & $19,8 \pm 11,5$ & $22,4 \pm 12,1$ & 0,36 \\
\hline
\end{tabular}

Veriler ortalama değerlerdir, \pm standart sapma değerleridir, $n$; hasta sayısı olarak verildi. p $<0,05$ anlamlı kabul edildi, NAC: N-Asetil Sistein, ABH: akut böbrek hasarı

Tablo 4. Farklı yöntemlere göre çalışmamızdaki ABH tanısı oranları

\begin{tabular}{|l|c|c|}
\hline & ABH var & ABH yok \\
\hline KDIGO (n, \%) & $26(74,3)$ & $9(25,7)$ \\
\hline RIFLE-F (n, \%) & $6(17,1)$ & $29(82,8)$ \\
\hline KDIGO-evre 3 (n, \%) & $8(22,9)$ & $27(77,1)$ \\
\hline
\end{tabular}

n; hasta sayısı olarak verildi, ABH: akut böbrek hasarı,

KDIGO: Kidney Disease: Improving Global Outcomes, RIFLE-F: Risk, Injury,

Failure, Loss of Kidney Function, and End-stage Kidney Disease Failure 


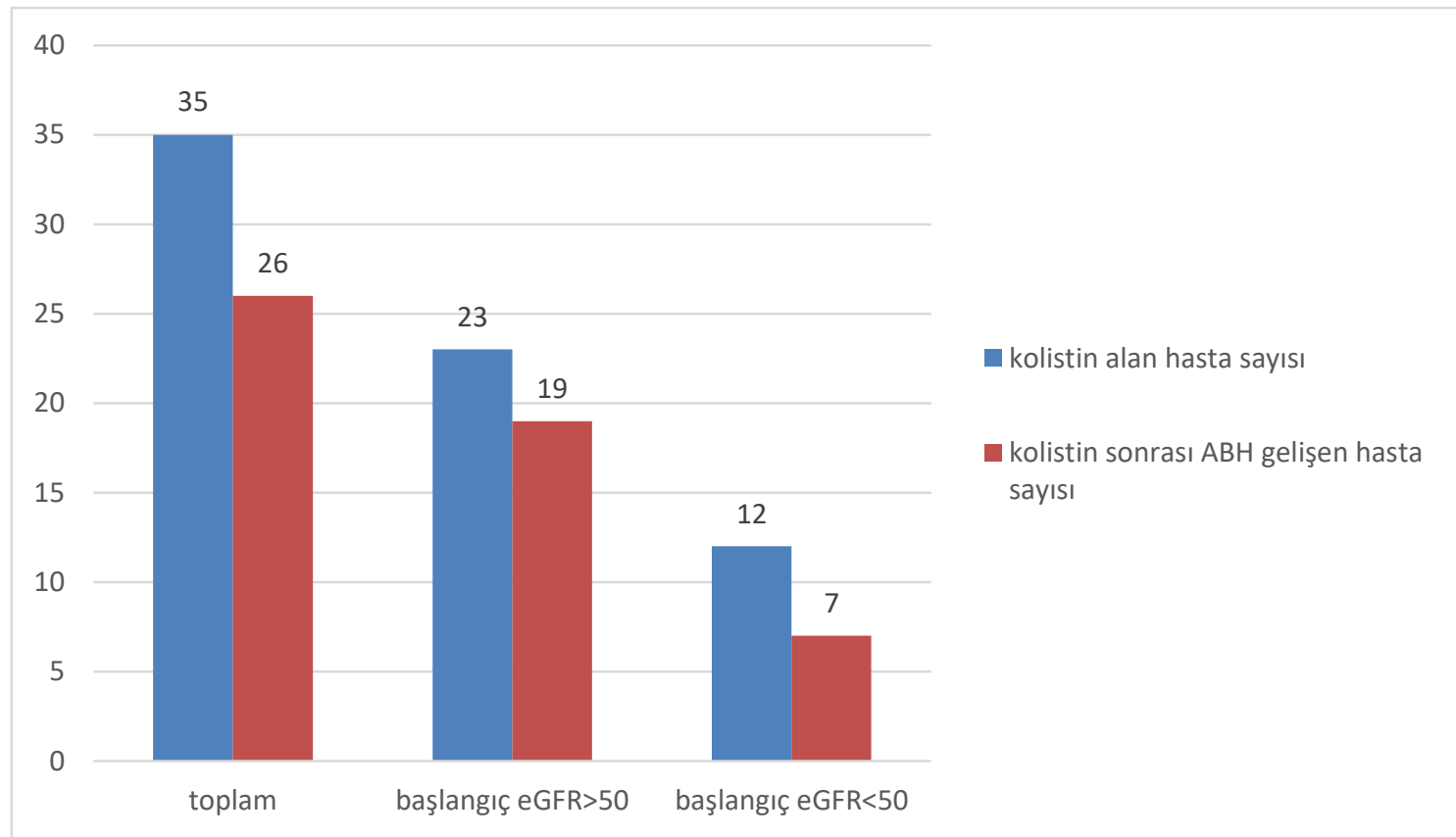

Şekil 1. Kolistin kullanımı sonrası $\mathrm{ABH}$ gelişen hastalar, hastane yatış günündeki eGFR değerine göre dağılımları

(ABH: akut böbrek hasarı, eGFR: tahmini glomerüler filtrasyon hızı-estimated glomerular filtration rate)

\section{REFERENCES}

1. Spapen H, Jacobs R, Van Gorp V, Troubleyn J, Honoré PM Renal and neurological side effects of colistin in critically ill patients. Ann Intensive Care (2011). 1(1):1-7

2. John E, Bennett RD, Blaser MJ Polymyxins (Polymyxin B and Colistin). In: Mandell, Douglas, and Bennett's principles and practice of infectious diseases. 8 edn. Elsevier Saunders, Canada, 2015, pp 549-555

3. Jo SH. N-acetylcysteine for Prevention of Contrast-Induced Nephropathy: A Narrative Review. Korean Circ J. 2011 Dec;41(12):695702.

4. Ozyilmaz E, Ebinc FA, Derici U, Gulbahar O, Goktas G, Elmas C ve ark.Could nephrotoxicity due to colistin be ameliorated with the use of $\mathrm{N}$-acetylcysteine? Intensive Care Med 2011 Jan;37(1):141-6.

5. Seetal Dodd, Olivia Dean, David L Copolov, Gin S Malhi, Michael Berk. N-acetylcysteine for antioxidant therapy: pharmacology and clinical utility. Expert Opin. Biol. Ther. (2008) 8(12).

6. Cockcroft DW, Gault MH. Prediction of creatinine clearance from serum creatinine. Nephron. 1976;16(1):31-41.
7. Kidney Disease: Improving Global Outcomes (KDIGO) Acute Kidney Injury Work Group. KDIGO Clinical Practice Guideline for Acute Kidney Injury. Kidney inter, Suppl. 2012; 2: 1138.

8. Rinaldo B, Claudio R, John AK, Ravindra LM, Paul $P$ and the ADQI work group. Acute renal failure - definition, outcome measures, animal models, fluid therapy and information technology needs: the Second International Consensus Conference of the Acute Dialysis Quality Initiative (ADQI) Group Critical Care2004 8:R204

9. Li J, Nation RL, Turnidge JD, Milne RW, Coulthard K, Rayner CR, et al. Colistin: the re-emerging antibiotic for multidrugresistant Gram-negative bacterial infections. (2006) Lancet Infectious Diseases, 6 (9), pp. 589-601.

10. Alejandro A, Sergio M, Gisela R, Helia B, Mariana D, Gerardo GR. Colistin in the postantibioticera. Revistachilena de infectología, (2016). 33(2), 166-176.

11. Dhariwal AK, Tullu MS. Colistin: Reemergence of the 'forgotten' antimicrobial agent. J Postgrad Med 2013; 59:208-15

12. Serdar G, Ferit K, Hande A, Dogan BO, Ozcan $\mathrm{D}$, Fazilet $\mathrm{D}$ ve ark. Original Article Risk Factors for Colistin-Associated Acute Kidney 
Injury: A Multicenter Study from Turkey. Jpn. J. Infect. Dis. 2016. 69, 109-112

13. Yahav D, Farbman, L. Leibovici, Paul $M$. Colistin: new lessons on an old antibiotic. Clinical Microbiology and Infection ,2012, Volume 18, Issue 1, 18- 29

14. Ülger F, Pehlivanlar Küçük M, Küçük A, İlkaya N, MuratN, Bilgiç B,Abanoz H. Evaluation of acute kidney injury (AKI) with RIFLE, AKIN, CK, and KDIGO in critically ill trauma patients. Eur J Trauma Emerg Surg 2018 Aug;44(4):597-605.

15. Tsai TY, Chien H, Tsai FC, Pan HC, Yang HY, Lee SY et al. Comparison of RIFLE, AKIN, and KDIGO classifications for assessing prognosis of patients on extracorporeal membrane oxygenation. J Formos Med Assoc. 2017 Nov;116(11):844-851.

16. Samuni Y, Goldstein S, Dean OM, Berk M. The chemistry and biological activities of $\mathrm{N}$ acetylcysteine. Biochim Biophys Acta. 2013;1830(8):4117-4129.

17. Atkinson MC. Theuse of $\mathrm{N}$-acetylcysteine in intensive care. Crit Care Resusc. 2002;4(1):2127.

18. Aitio ML. N-acetylcysteine. passe-part out or much ado about nothing? Br J Clin Pharmacol. 2006;61(1):5-15.

19. M. Gawenda, A. Möller, G. Wassmer, J. Brunkwall. N-Acetylcystein in der Prophylaxe der Kontrastmittel-induzierten Nephropathie Prophylaxis of Contrast-Induced Nephropathy with N-Acetylcysteine. Zentralbl Chir 2007;132(3): 227-231 DOI: 10.1055/s-2007960756.

20. Emet $S$, Memis D, Pamukcu Z. The influence of $\mathrm{N}$-acetyl-L cystein infusion on cytokine levels and gastric intramucosal $\mathrm{pH}$ during severe sepsis. Crit Care. 2004;8(4): R172-R179.

21. Spapen H, Zhang H, Demanet C, Vleminckx W, Vincent JL, Huyghens L. Does N-acetyl-Lcysteine influence cytokine response during early human septic shock? Chest. 1998;113(6): 1616-1624.

22. Luo J, Tsuji T, Yasuda H, Sun Y, Fujigaki Y, Hishida A. The molecular mechanisms of the attenuation of cisplatin-induced acute renal failure by $\mathrm{N}$-acetylcysteine in rats. Nephrol Dial Transplant. 2008; 23:2198-2205.

23. Efrati S, Averbukh M, Berman S, Leonid F, Dishy V, Kachko L et al. N-Acetylcysteine ameliorates lithium-induced renal failure in rats. Nephrol Dial Transplant. 2005; 20:65-70.

24. Chen N, Aleksa K, Woodland C, Rieder M, Koren G. N-Acetylcysteine prevents ifosfamide-induced nephrotoxicity in rats. $\mathrm{Br} \mathrm{J}$ Pharmacol. 2009; 153:1364-1372

25. Ocak S, Gorur S, Hakverdi S,Celik S, Erdogan S.Protective effects of caffeic acid phenethyl ester, vitamin $\mathrm{C}$, vitamin $\mathrm{E}$ and $\mathrm{N}$-acetylcysteine on vancomycin-induced nephrotoxicity in rats. Basic Clin Pharmacol Toxicol. 2007;100: 328333.

26. Borisenok OA, Bushma MI, Baraban OV, Zimatkin SM. Therapeutic effect of acetylcysteine on rats with gentamicin-induced nephropathy. Eksp Klin Farmakol. 2012; 75:1013.

27. Odabasi Z, Karaalp A, Cermik H, Mohr J, Tigen ET, Koc M et al. Reduction of amphotericin Binduced renal tubular apoptosis by $\mathrm{N}$ acetylcysteine. Antimicrob Agents Chemother. 2009; 53:3100-3102.

28. Weisbord SD, Gallagher M, Jneid H, Garcia S, Cass A, Thwin SS et al. PRESERVE Trial Group. Outcomes after Angiography with Sodium Bicarbonate and Acetylcysteine. N Engl J Med. 2018; 378:603-614.

29. Ceylan B, Ozansoy M, Kılıç Ü, Yozgat Y, Ercan Ç,Yıldız P et al. (2018) N-acetylcysteine suppresses colistimethate sodium-induced nephrotoxicity via activation of SOD2, eNOS, and MMP3 protein expressions. Renal Failure, 40:1, 423-434

30. Mei Mei MM, Hong-Wen Zhao MD, QianGuang Pan MM, You-Min Pu MM, Mao-Zhi Tang MM \& Bing-Bing Shen MD: Efficacy of N-Acetylcysteine in Preventing Acute Kidney Injury After Cardiac Surgery: A Meta-Analysis Study, Journal of Investigative Surgery. J Invest Surg. 2018 Feb;31(1):14-23 DOI: $10.1080 / 08941939.2016 .1269853$ 